\title{
A New Subgroup of Lectin-bound Biliary Proteins Binds to Cholesterol Crystals, Modifies Crystal Morphology, and Inhibits Cholesterol Crystallization
}

Norbert Busch, Frank Lammert, Hanns-Uirich Marschall, and Siegfried Matem

Department of Internal Medicine III, Aachen University of Technology, 52057 Aachen, Germany

\begin{abstract}
Biliary proteins inhibiting or promoting cholesterol crystallization are assumed to play a major role in cholesterol gallstone pathogenesis. We now report a new group of biliary proteins that bind to cholesterol crystals, modify crystal morphology, and inhibit cholesterol crystallization. Various glycoprotein mixtures were extracted from abnormal human gallbladder bile using lectin affinity chromatography on concanavalin A, lentil, and Helix pomatia columns and were added to supersaturated model bile. Independent of the protein mixtures added, from the cholesterol crystals harvested, the same four GPs were isolated having molecular masses of 16, 28, 63, and $74 \mathrm{kD}$, respectively. Each protein was purified using preparative SDS-PAGE, and influence on cholesterol crystallization in model bile was tested at $10 \mu \mathrm{g} / \mathrm{ml}$. Crystal growth was reduced by $76 \%$ (GP63), $65 \%$ (GP16), 55\% (GP74), and 40\% (GP28), respectively. Thus, these glycoproteins are the most potent biliary inhibitors of cholesterol crystallization known so far. Evidence that the inhibiting effect on cholesterol crystallization is mediated via protein-crystal interaction was further provided from scanning electron microscopy studies. Crystals grown in presence of inhibiting proteins showed significantly more ordered structures. Incidence of triclinic crystals and regular aggregates was shifted from 30 to $70 \%$ compared with controls. These observations may have important implications for understanding the role of biliary proteins in cholesterol crystallization and gallstone pathogenesis. (J. Clin. Invest. 1995. 96:3009-3015.) Key words: gallstone $\cdot$ cholesterol crystallization $\cdot$ bile $\bullet$ inhibitor $\bullet$ biliary proteins
\end{abstract}

\section{Introduction}

Evidence was provided almost a decade ago that biliary proteins play an important role in cholesterol crystallization (1-3). By

Portions of this study were presented at the 43rd annual meeting of the American Association for the Study of Liver Disease in Chicago, IL on 3 November 1992 and published in abstract form (Hepatology. 1992. 16:124a).

Address correspondence to Norbert Busch, Department of Internal Medicine III, Aachen University of Technology, 52057 Aachen, Germany. Phone: 49-241-8089507; Fax: 49-241-8888455.

Received for publication 21 June 1995 and accepted in revised form 8 September 1995.

J. Clin. Invest.

(C) The American Society for Clinical Investigation, Inc.

$0021-9738 / 95 / 12 / 3009 / 07 \$ 2.00$

Volume 96, December 1995, 3009-3015 combining lectin affinity chromatography and a newly developed crystal growth assay (4) in a systematic study, various glycoprotein mixtures were separated from normal human bile, some of which primarily promoted and others primarily inhibited crystallization (5). Inhibiting activity was most potent in the Helix pomatia lectin-bound fraction from which a $120-\mathrm{kD}$ heterodimer glycoprotein was isolated with subunits of 58 and $63 \mathrm{kD}(6)$. Inhibiting potency of the heterodimer, however, was lower than the effect of total Helix pomatia lectin-bound fraction indicating other inhibitors do exist. In this study we report a new subgroup of four biliary glycoproteins that adsorb to cholesterol crystals. Using this feature, we were able to identify and isolate these proteins from lectin-bound mixtures. All four glycoproteins are potent inhibitors of cholesterol crystal growth. Scanning electron microscopy reveals significant differences in crystal morphology when crystals are grown in the presence of these proteins. Our studies provide novel insights into the mechanism of action of biliary inhibitor proteins.

\section{Methods}

Chemicals. Sodium salts of taurocholic acid and taurodeoxycholic acids, $\alpha$-D-methyl-mannopyranoside, and $N$-acetyl- $\alpha$-D-galactosamine were obtained from Sigma Chemical Co. (St. Louis, MO), cholesterol from Eastman Kodak (Rochester, NY), and grade I egg yolk lecithin from Lipid Products (South Nutfield, UK). Concanavalin A (Con A) ${ }^{1}$ Sepharose 4B, lentil lectin-sepharose 4B, Helix pomatia lectin-sepharose $6 \mathrm{MB}$, Pharmalyt $^{\mathrm{TM}} 3-10$, and Immobiline ${ }^{\mathrm{TM}}$ Dry Strips were obtained from Pharmacia Fine Chemicals (Uppsala, Sweden). SDS, $\beta$-mercaptoethanol, acrylamide, bisacrylamide, ammonium persulfonate, and TEMED $\left(N, N, N^{\prime}, N^{\prime}\right.$-tetramethylene diamine) were purchased from Bio-Rad Laboratories (Richmond, CA). All other chemicals and solvents were reagent or HPLC grade quality (Merck AG, Darmstadt, Germany; Fluka Chemie AG, Buchs, Switzerland; J. T. Baker Inc., Deventer, Netherlands). Glassware was washed in warm $2 \%$ (vol/vol, $60^{\circ} \mathrm{C}$ ) detergent solution (PCC-54 ${ }^{\mathrm{TM}}$; Pierce Chemical Co., Rockford, IL), followed by methanol washes and thorough rinsing with purified water before drying. The water was of Milli-Q-quality (Millipore Corp., Bedford, MA). Solutions were filtered through $0.22-\mu \mathrm{m}$ micropore filters (Millipore Corp.) and degassed before use for model bile preparation.

Analytical procedures. Lipids were quantified enzymatically (7-9) using commercially available kits for bile acids (Nycomed Pharmaceuticals, Oslo, Norway), lecithin (Texas International Laboratories, Houston, TX), and cholesterol (Boehringer Mannheim, Mannheim, Germany). Protein concentrations were measured using either the Coomassie blue dye-binding assay (Bio-Rad Laboratories) (10) or the bicinchoninic acid combined biuret method (Pierce Chemical Co.) (11).

1. Abbreviations used in this paper: Con A, concanavalin A; GP, glycoprotein; $I_{c}$, concentration index; $I_{g}$, growth rate index; TBS, Tris-buffered saline. 
SDS-PAGE. Gels were run in the buffer system described by Laemmli (12) in a vertical electrophoresis cell under reducing conditions. Lyophilized proteins ( $1 \mu \mathrm{g}$ ) were resolubilized with $10 \mu \mathrm{l}$ sample buffer containing $50 \mathrm{mM}$ Tris- $\mathrm{HCl}, \mathrm{pH} 6.8$, containing $2 \%$ (wt/vol) SDS, $10 \%(\mathrm{vol} / \mathrm{vol})$ glycerol, $10 \%$ (vol $/ \mathrm{vol}) \beta$-mercaptoethanol, $0.004 \%$ (wt/vol) bromphenol blue, and $1 \mathrm{mM}$ EDTA and heated for $10 \mathrm{~min}$ at $95^{\circ} \mathrm{C}$ before loading to the gel (polyacrylamide gradient $8-18 \%, 0.1 \%$ SDS, cell: Biometra ${ }^{\mathrm{TM}}$ Minigel G-41; Biomedizinische Analytik GmbH, Göttingen, Germany). After completion of electrophoresis, proteins were fixed in the gels for $30 \mathrm{~min}$ in a watery solution of $40 \%$ ethanol and $10 \%$ acetic acid (vol/vol) and stained with silver nitrate (13).

For preparative electrophoresis, $100 \mu \mathrm{g}$ of lyophilized Helix pomatia lectin-bound proteins were resolubilized in $100 \mu \mathrm{l}$ sample buffer containing $0.2 \%$ (wt/vol) SDS, and incubated for $12 \mathrm{~h}$ at $25^{\circ} \mathrm{C}$ before separation in a homogeneous $15 \%$ polyacryamide gel $(125 \times 125 \times 0.75$ $\mathrm{mm}^{3}, 0.1 \%$ SDS, cell: 2001; LKB, Uppsala, Sweden). Protein bands were identified using reversible staining (Copper Stain; Bio-Rad Laboratories). Corresponding gel segments were cut, destained, and proteins were recovered by electroelution (422; Bio-Rad Laboratories) using a $50-\mathrm{mM}$ ammonium bicarbonate $/ 0.005 \%$ SDS (wt/vol) elution buffer. Matched gel segments without proteins were equally processed and used as equivalent internal control.

Isoelectric focusing and two-dimensional gel electrophoresis. Analytical isoelectric focusing was performed according to manufacturer's protocol using gels with immobilized $\mathrm{pH}$ gradients (Immobiline ${ }^{\mathrm{TM}}$ Dry Strips, pH gradient 3-10; Pharmacia Fine Chemicals) (14). Lyophilized protein samples $(3 \mu \mathrm{g})$ were resolubilized before loading to the gel strips in $8 \mathrm{M}$ urea, $0.5 \%$ (vol/vol) Triton X 100, $10 \mathrm{mM}$ DTT, $4 \%$ ( vol/vol) Pharmalyte ${ }^{\mathrm{TM}} 3-10,10 \%$ ( vol/vol) glycerol, and $8 \mathrm{mM}$ PMSF. After isoelectric focusing, gel strips were equilibrated twice for $10 \mathrm{~min}$ in a buffer solution of $50 \mathrm{mM}$ Tris- $\mathrm{HCl}, \mathrm{pH} 6.8$, containing $1 \%$ (wt/vol) SDS, $16 \mathrm{mM}$ DTT, $1 \mathrm{mM}$ EDTA, $6 \mathrm{M}$ urea, 30\% (vol/vol) glycerol, and $0.01 \%(\mathrm{~g} / \mathrm{vol})$ bromphenol blue. The strips were then applied tightly to the stacking gel of a vertical polyacryamide gel (gradient 8-18\%, LKB 2001 cell) and electrophoresis, followed by silver staining, was carried out as described above.

Protein separation by lectin affinity chromatography. Samples of human gallbladder bile were obtained by needle aspiration from patients undergoing cholecystectomy. Only biles of cholesterol gallstone patients, judged by macroscopic examination of the stones, were used without further analysis of the biliary lipid concentrations. The collection protocol of this abnormal bile was approved by the local ethics committee. Gallbladder aspirates were cultured to exclude bacterial infection and tested for blood contamination (colo-rectal test; Hoffmann-La Roche, Basel, Switzerland). Only negative samples were used. Samples were stored under nitrogen at $-70^{\circ} \mathrm{C}$ up to $6 \mathrm{mo}$. Pooled bile specimens were ultracentrifuged for $1 \mathrm{~h}$ at $100,000 \mathrm{~g}$ at $4^{\circ} \mathrm{C}$ to remove insoluble constituents. The soluble phase was directly loaded to either a concanavalin $\mathrm{A}$ or a lentil lectin column $(1 \mathrm{ml}$ bile $/ 1 \mathrm{ml}$ gel $)$ and recycled for $12 \mathrm{~h}$. Before loading the sample, columns $(50 \mathrm{ml}$ gel in a column of $2.5 \times 20 \mathrm{~cm}$ ) were prewashed with $250 \mathrm{ml} 20 \mathrm{mM}$ Tris- $\mathrm{HCl}$ starting

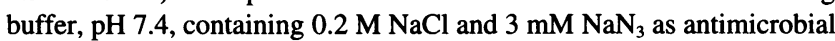
agent. After recycling, all unbound components were removed from the column by washing with $>250 \mathrm{ml}$ of starting buffer containing $3 \mathrm{mM}$ sodium taurocholate until optical density of the eluent reached constant values. Subsequently, bound fractions were eluted with $250 \mathrm{ml}$ of starting buffer supplemented with $0.25 \mathrm{M} \alpha$-D-methylmannopyranoside. The lectin-bound fractions were concentrated to $10 \mathrm{ml}$ by ultrafiltration, and buffer was exchanged to $20 \mathrm{mM}$ ammonium bicarbonate by diafiltration on a YM 10 filter (Amicon Corp., Danvers, MA). Aliquots of both lectin-bound glycoprotein fractions were further purified by chromatography on a Helix pomatia lectin column $(20 \mathrm{ml}$ gel in $2.5 \times 20 \mathrm{~cm}$ column, $0.5 \mathrm{mg}$ protein $/ \mathrm{ml}$ gel) using the same procedure as described above. The bound glycoproteins were eluted with $100 \mathrm{ml}$ starting buffer supplemented with $0.5 \mathrm{M} N$-acetyl- $\alpha$-D-galactosamine.

Model bile. Concentrations of stock solutions (taurocholate and cholesterol, both in methanol, and lecithin in chloroform-methanol 2:1 [ vol/ vol]) were determined as described above. Appropriate aliquots of stock solutions were calculated from Carey's critical tables (15), coprecipitated, dried under nitrogen, and subsequently lyophilized as previously described (4). The dried lipid film was dissolved in Tris-buffered saline (TBS) ( $25 \mathrm{mM}$ Tris- $\mathrm{HCl}, \mathrm{pH} 7.45,150 \mathrm{mM} \mathrm{NaCl}$ ) containing $3 \mathrm{mM}$ $\mathrm{NaN}_{3}$. The suspension was then incubated at $60^{\circ} \mathrm{C}$ for $6 \mathrm{~h}$, and the clear solution was filtered through a preheated $0.22-\mu \mathrm{m}$ filter assembly (Swinny; Millipore Corp.), flushed with nitrogen, and equilibrated to $37^{\circ} \mathrm{C}$ for $15 \mathrm{~min}$ before further use (final parameters: cholesterol saturation index, 1.3; total lipid concentration, $125 \mathrm{~g} /$ liter; bile acid/phospholipid ratio, 4:1).

Cholesterol crystal growth assay. Cholesterol crystal growth in model bile was measured as previously described (4). Briefly, aliquots of proteins or the equivalent control (see SDS-PAGE) were lyophilized in the reaction vials, resolubilized with $40 \mu \mathrm{l}$ TBS, and equilibrated at $37^{\circ} \mathrm{C}$. Model bile $(460 \mu \mathrm{l})$ was added to each vial. After flushing with nitrogen the vials were covered with Teflon-lined screw caps, incubated at $37^{\circ} \mathrm{C}$, and shaken at $100 \mathrm{rpm}$. To determine crystal concentration in the reaction mixture, an aliquot of $20 \mu \mathrm{l}$ was diluted with $460 \mu \mathrm{l}$ TBS/ $10 \mathrm{mM}$ taurodeoxycholic acid, and absorbance was measured at 500 $\mathrm{nm}$ using a spectrophotometer (Response ${ }^{\mathrm{TM}}$; Gilford Instrument Laboratories, Inc., Oberlin, $\mathrm{OH}$ ). For comparison, graphs of each protein were normalized by setting to the final plateau of each individual control to unity. Effects of proteins on cholesterol crystal growth were assessed by the crystal growth rate index $\mathrm{I}_{\mathrm{g}}$ (maximum slope of protein curve/ control curve ) and crystal concentration index $I_{c}$ ( final plateau of protein curve/control curve) as described previously (4).

Preparation of crystal adsorbed proteins. Aliquots of lyophilized lectin-bound glycoprotein solutions were resolubilized with $200 \mu \mathrm{l}$ TBS before mixing with $2.3 \mathrm{ml}$ freshly prepared model bile. Samples were kept under nitrogen at $37^{\circ} \mathrm{C}$ and shaken at $100 \mathrm{rpm}$. After $6 \mathrm{~d}$, cholesterol crystals were harvested from each sample by filtration through a 0.45 $\mu \mathrm{m}$ microfilter (Millipore Corp.) To totally remove lipids and impurities of model bile solution, crystals were resuspended in $10 \mathrm{ml}$ TBS containing $1 \mathrm{mM}$ taurocholic acid and separated from the solution by centrifugation at $10,000 \mathrm{~g}$ at $4^{\circ} \mathrm{C}$. This procedure was repeated twice. Complete removal of possibly coprecipitated unbound proteins was checked by sucrose density gradient centrifugation followed by SDS-PAGE. To recover bound proteins, crystals were solubilized in $30 \mathrm{ml}$ 2-propanol, and diafiltration was performed with $300 \mathrm{ml}$ of 2-propanol on a filter (cut-off $10 \mathrm{kD}$ ) (YM 10; Amicon Corp.) to remove cholesterol. The solution was then concentrated in the Amicon unit to $1 \mathrm{ml}$, and solvent was exchanged to $25 \mathrm{mM}$ ammonium bicarbonate. The protein solution was divided into two fractions that were lyophilized and further analyzed by either SDS-PAGE or two-dimensional-electrophoresis.

Crystal morphology studies. A small amount of washed crystals was examined by scanning electron microscopy (SEM 515; Philips, Eindhoven, Netherlands; beam accelerating voltage $20 \mathrm{kV}$ ) after air drying and gold coating. For this purpose, an aliquot of crystal suspension after the final wash was filtered on $0.22-\mu \mathrm{m}$ filter. Probes were either processed directly or after transfer to glass slides. Distribution of crystal structures in the populations of the various growth experiments was quantified by classifying 150 crystals in randomly selected visual fields under the electron microscope according to the characteristic morphological features discussed in Results.

Statistical analysis. The distribution of cholesterol crystals was analysed using StatXact (CYTEL Software Corp., Cambridge, MA). Overall homogeneity was tested in a 4 by 4 contingency table. Distributions of crystals grown with effector proteins were individually compared to control and among each other using the exact test for 2 by 4 contingency tables. Distribution across the different morphological classes in presence or absence of effector proteins was tested using Fisher's exact test for 2 by 2 tables.

Cholesterol crystal growth curves were analyzed using split plot ANOVA to determine differences between study groups assigning the time to be the split factor. Sequential multiple comparisons were performed at the $5 \%(P<0.05)$ level using the procedure of Bonferonni (16). 


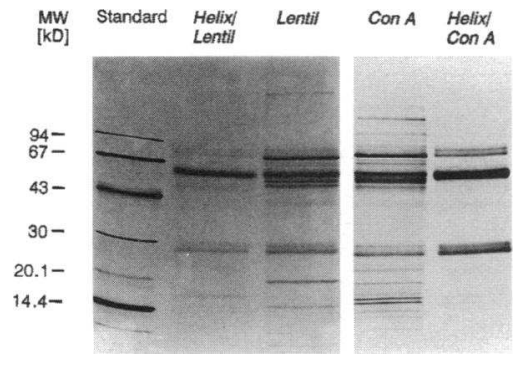

Figure 1. SDS-PAGE under reducing conditions of the four protein fractions separated from abnormal human bile by various lectin affinity chromatography. Silver stain.

\section{Results}

Crystal-binding proteins. Protein fractions bound to Con A and lentil lectins differed significantly in number of bands and relative distributions of proteins when compared by SDS-PAGE (Fig. 1), although both columns are supposed to have similar binding specificity. This is in agreement with separations using molecular sieving chromatography before lectin affinity chromatography (5). Recovery of proteins was $\sim 10 \%$ for the Con $\mathrm{A}$ and $5 \%$ for lentil lectin columns. Using subsequent chromatography on a Helix pomatia lectin column, the protein mixture separated showed the same number and positions of protein bands. However, different intensities of individual bands were observed corresponding to differences in relative amounts of proteins.

From each of the four lectin-bound fractions we determined the proteins that attach to cholesterol crystals grown in model bile solutions at $\mathrm{pH} 7.45$. Independent of the fraction added to the model bile, we isolated the same set of crystal-binding proteins. This new subgroup is formed by four proteins having molecular masses of $16,28,63$, and $74 \mathrm{kD}$, respectively (Fig. 2 , bottom). Each protein band consisted of several isoforms with $\mathrm{pI}$ in the range of $\mathrm{pH} 6.3-8.3$ as determined by twodimensional gel electrophoresis. The smeared background in the range of $50-80 \mathrm{kD}$ resulted from traces of cholesterol in the crystal-bound protein samples. Comparing the two-dimensional gels of proteins bound to cholesterol crystals with those of the lectin-bound proteins that were added to model bile before starting crystal growth (Fig. 2, top), we found only isoforms binding to crystals with $\mathrm{pI}$ within $\pm 1 \mathrm{pH} \mathrm{U}$ of the model bile $\mathrm{pH}$.

Crystal morphology. Scanning electron microscopy studies were performed to assess changes in crystal morphology when grown in the presence of effector proteins. We found the following typical classes of crystals sufficient to characterize populations of crystals grown in our experiments (Fig. 3).

The basic unit was the platelike crystal showing either the euhedral triclinic form with straight edges and a smooth surface or the polycyclic form with multiple cyclic edges and many screwed and stepwise dislocations (Fig. 3, 1 and 4). These crystal plates tended to aggregate in a fashion in which the euhedral crystals mainly formed aggregates orderly aligned along the main crystallographic axes of the triclinic crystal, while polycyclic plates preferred random aggregation (Fig. 3, 2 and 5). In addition, we found polycyclic plates radially arranged thus forming a cluster of $\sim 200 \mu \mathrm{m}$ opening up widely into space (Fig. 3,6 ). In contrast, we also found radial arrangements of smooth triclinic crystal plates with little free space between the plates representing small compact microliths (Fig. 3, 3). Remarkably, some euhedral crystals exhibited the shape

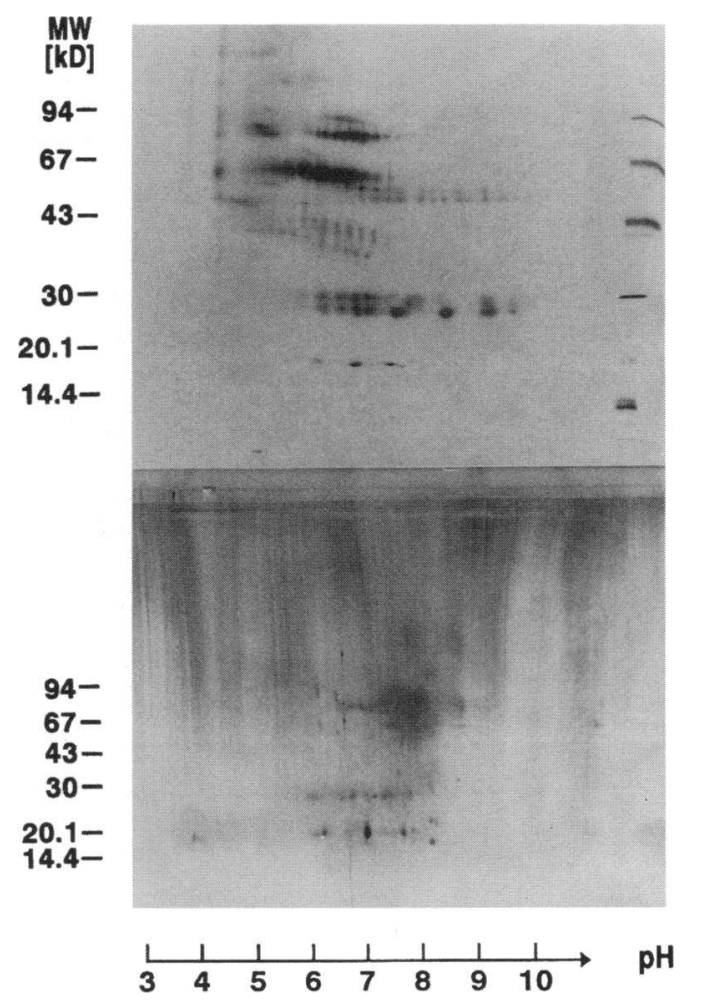

Figure 2. Two-dimensional electrophoresis of the Lentil lectin-bound fraction (top) and the crystal-binding proteins (bottom). Proteins were separated in first step using Immobiline ${ }^{\mathrm{TM}}$ strips, $\mathrm{pH}$ gradient 3-10, followed by SDS-PAGE under reducing conditions in the second dimension as described under methods. Silver stain.

of thick rhombic crystal plates with smooth surfaces and only few dislocations (Fig. 3, 8). These compact microliths were observed in particular at the end of the growth experiments and may be considered as the most effective deposit for cholesterol. Some concrements were seen with an irregular surface unlike typical platelike cholesterol crystals. These are referred to as amorphous concrements in Fig. 3, 9. In addition, only in early stages of crystal growth, we saw many rodlike structures with drumsticklike augmentations at one end representing evolving crystal plates (Fig. 3, 7). These structures have recently been described by Konikoff et al. (17).

To quantify effects on crystal morphology we determined the distribution of cholesterol crystals across the characteristic classes at the end of the various growth experiments. In each population, we classified 150 crystals in randomly selected visual fields of the electron microscope. Euhedral crystals and regular aggregates were combined to one class, and the polycyclic crystals and their irregular aggregates to another one. Table I gives the relative frequencies of crystals in the populations grown in identical aliquots of supersaturated model bile supplemented with the different lectin-bound fractions in comparison to control.

After spontaneous growth without effectors, we found polycyclic crystals and their random aggregates accounting for 58\% of all crystals. Euhedral crystals and their regular aggregates were found less frequently (29\%). A significant number of large clusters $(5 \%)$ was only observed in control populations. The distribution of amorphous concrements was approximately 

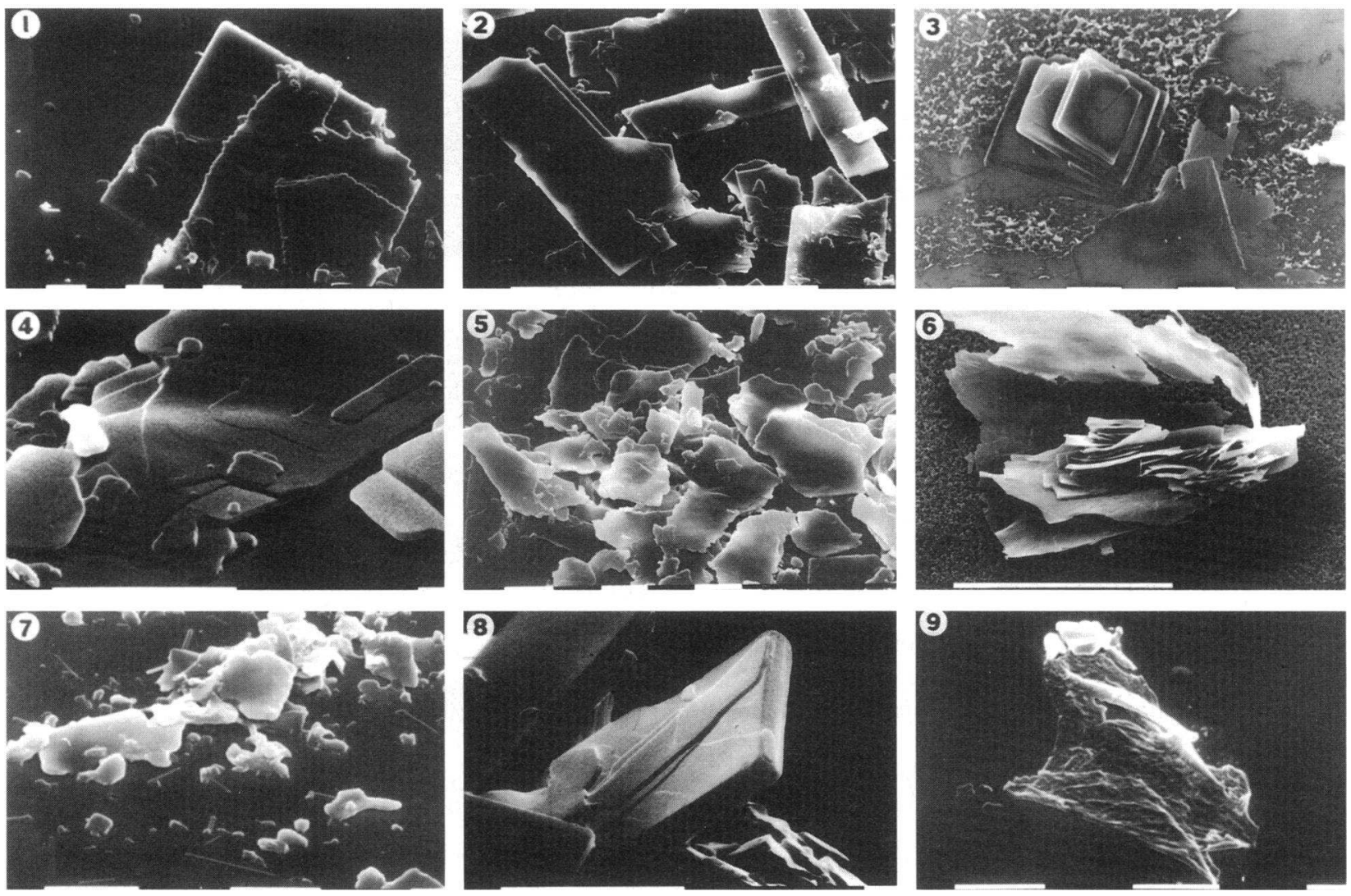

Figure 3. Representative scanning electron micrographs of the characteristic classes of cholesterol crystals. (1) Euhedral triclinic crystal plate; (2) regular aggregates; (3) compact microliths; (4) polycyclic crystal plates; (5) random aggregates; (6) cluster of radially arranged polycyclic plates; (7) random aggregates and rodlike structures showing augmentations at one end representing evolving crystal plates; $(8)$ compact triclinic crystal plate; and (9) amorphous concrement. In the presence of lectin-bound proteins, structures $1-3$ and 8 were found most frequently. In control, structures 4-6 were predominant. Bars represent $100 \mu \mathrm{m}$ in 2 and $6 ; 10 \mu \mathrm{m}$ in all other micrographs.

the same in all experiments. The picture was quite different when crystals were grown in the presence of lectin-bound biliary effector proteins. Compared to control, these populations showed a marked increase in frequencies of regular crystal forms $(60-70 \%)$ and a decrease in irregular structures to $\sim 30 \%$. The incidences of these two classes were almost inverted compared to control. Since both Helix pomatia lectin-

Table I. Relative Distribution of the Different Structures of Cholesterol Crystals

\begin{tabular}{lrrrr}
\hline \multicolumn{1}{c}{ Sample } & Control & $\begin{array}{c}\text { Helix } \\
100^{*}\end{array}$ & $\begin{array}{c}\text { Con A } \\
500^{*}\end{array}$ & $\begin{array}{c}\text { Lentil } \\
500^{*}\end{array}$ \\
\hline & $\%$ & $\%$ & $\%$ & $\%$ \\
Polycyclic crystals, random aggregates & $58^{\ddagger}$ & 33 & 27 & 28 \\
Triclinic crystals, regular aggregates & $29^{\ddagger}$ & 59 & 67 & 70 \\
Amorphous concrements & $8^{8}$ & 7 & 6 & 2 \\
Clusters & $5^{\|}$ & 1 & 0 & 0
\end{tabular}

Relative distribution of the different structures of cholesterol crystals in the populations harvested from model bile after spontaneous growth (Control) compared to crystals grown in presence of three biliary effector protein fractions (bound to Helix pomatia, Con A, and lentil lectins). ${ }^{*}$ Micrograms protein per milliliter model bile; ${ }^{\ddagger} P<0.001$; ${ }^{8}$ not significant; " $P<0.004$. bound fractions induced the same effect on crystal morphology, the numbers in Table I represent mean values. Statistical analysis revealed a highly significant overall difference in distribution across the morphological classes $(P<0.001)$. All three proteinrelated distributions were significantly different from control $(P$ $<0.001)$ but not among each other $(P>0.1)$. Therefore, the three protein-related distributions were collapsed into one group, and the four morphological classes were compared to those of the control condition using Fisher's exact test for 2 by 2 tables. Polycyclic crystals and random aggregates $(P$ $<0.001)$ as well as clusters $(P<0.004)$ were significantly more frequent in control, whereas triclinic crystals and regular aggregates were significantly less frequent $(P<0.001)$. There was no significant difference in the incidence of amorphous concrements.

Cholesterol crystal growth. The four glycoproteins that had been identified by the crystal-binding studies were individually purified from the Helix pomatia lectin-bound fraction of abnormal human bile using preparative SDS-PAGE. A single band for each of the four glycoproteins was obtained as estimated by analytical SDS-PAGE gel with silver staining (Fig. 4). To assess their influence on cholesterol crystallization, we tested each protein at a final concentration of $10 \mu \mathrm{g} / \mathrm{ml}$ using the crystal growth assay in model bile (4). Control curves were measured in triplicate and protein-related curves were measured in duplicate. Growth curves were normalized to the final plateau of 


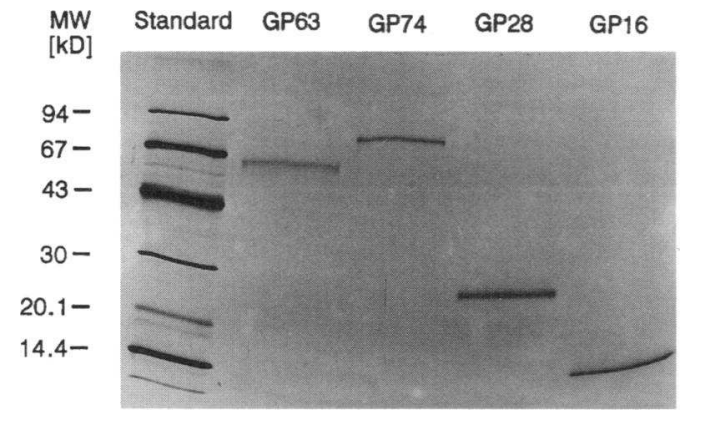

Figure 4. SDS-PAGE under reducing conditions of the four crystalbinding glycoproteins after purification from the Helix pomatia lectinbound fraction using preparative SDS-gel electrophoresis. Silver stain. $G P 63, G P 74, G P 28$, and GP16 refer to the four glycoproteins having molecular masses of $63,74,28$, and $16 \mathrm{kD}$, respectively.

each individual control curve. Compared to control, all four proteins proved to be potent inhibitors of cholesterol crystallization (Fig. 5). Both maximal crystal growth rate index $I_{g}$ and final crystal concentration index $I_{c}$ were significantly reduced by all four proteins. The most potent effect was measured for the 28-kD glycoprotein $\left(G P 28: I_{g}=0.39, I_{c}=0.46\right)$ followed by the 74-kD glycoprotein (GP74: $I_{g}=0.56, I_{c}=0.61$ ), and the $16-\mathrm{kD}$ glycoprotein (GP16: $I_{g}=0.63, I_{c}=0.69$ ). The inhibiting effect was lowest for the $63-\mathrm{kD}$ glycoprotein (GP63: $I_{g}=0.67, I_{c}=0.73$ ).

\section{Discussion}

Biliary proteins, either promoting or inhibiting cholesterol crystallization, are assumed to contribute to a balance of effects influencing the physical chemistry of supersaturated bile thereby modifying nucleation and growth of crystals $(18,19)$. These crystals probably agglomerate via mucin glycoproteins before forming mature cholesterol gallstones $(20,21)$.

Progress in purifying biliary effector proteins had been slow until lectin affinity chromatography was introduced to separate glycoproteins from bile $(22,23)$. Since then several crystallization-promoting proteins have been reported. These include a $130-\mathrm{kD}$ glycoprotein (23) which recently was shown to be aminopeptidase $\mathrm{N}(24)$, biliary Igs (25), $\alpha$-1 acid glycoprotein (26), phospholipase $C$ (27), and fibronectin (28). As to inhibiting activity, however, only a $120-\mathrm{kD}$ heterodimer glycoprotein with subunits of 58 and $63 \mathrm{kD}$ was isolated from Helix pomatia lectin-bound proteins of normal human bile (6).

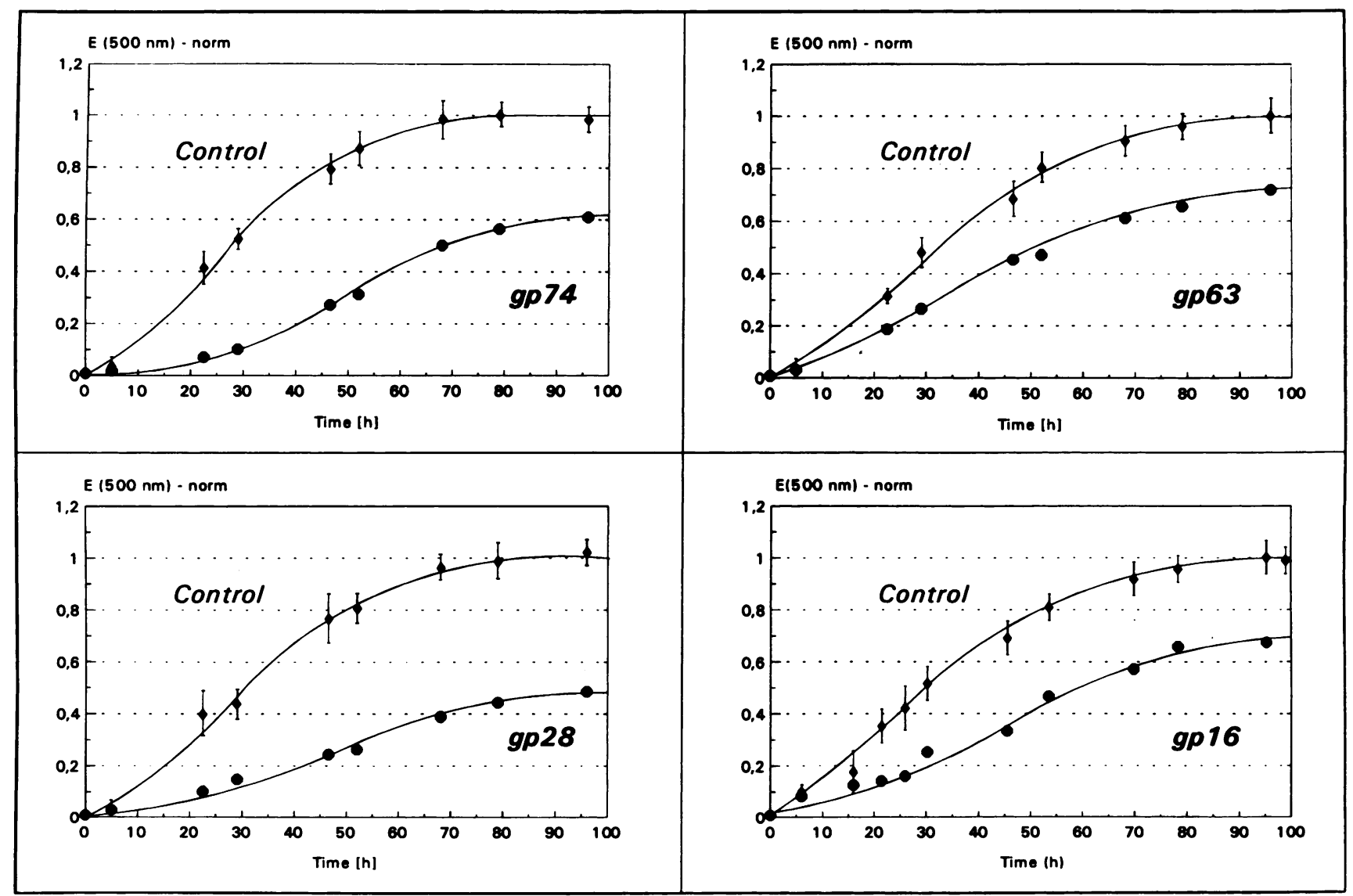

Figure 5. Comparative effect of the isolated glycoproteins $(10 \mu \mathrm{g} / \mathrm{ml})$ on cholesterol crystal growth curves in model bile. Crystal concentrations are proportional to the absorbance of the samples measured at $500 \mathrm{~nm}$. Graphs were normalized by setting the plateau of each individual control of the independent experiments to unity [Extinction (E) $(500 \mathrm{~nm})-$ norm]. Control curves are given as mean $\pm \operatorname{SD}(n=3)$. Each experimental curve is given as mean $(n=2)$. Differences between control and experimental curves were statistically significant: $P=0.001$ for $G P 28, G P 63$, and GP74; $P<0.05$ for GP16. Growth curve indices were calculated from measured values for each glycoprotein: GP74: $\mathrm{I}_{g}=0.56, \mathrm{I}_{\mathrm{c}}=0.61$; GP63: $\mathrm{I}_{\mathrm{g}}=0.67, \mathrm{I}_{\mathrm{c}}=0.73 ; \mathrm{GP16}: \mathrm{I}_{\mathrm{g}}=0.63, \mathrm{I}_{\mathrm{c}}=0.69 ; \mathrm{GP28}: \mathrm{I}_{\mathrm{g}}=0.39, \mathrm{I}_{\mathrm{c}}=0.46$. 
We report new data on inhibition of cholesterol crystallization by biliary proteins. A new subgroup of four glycoproteins was isolated from different lectin-bound protein fractions that were known to contain both promoting and inhibiting factors of cholesterol crystallization (5). The unique quality that we used to identify and isolate this subgroup of proteins was their ability to bind to cholesterol crystals, therefore we refer to these compounds as crystal-binding proteins. Analysis of the lectinbound protein fractions compared to the crystal-binding proteins by two-dimensional electrophoresis demonstrated that all four glycoproteins consist of several isoforms. Only those with pI within a range of $\pm 1 \mathrm{pH} \mathrm{U}$ around the $\mathrm{pH}$ of the model bile were capable of crystal binding. All four proteins were enriched using Helix pomatia lectin affinity chromatography, which is supposed to preferentially bind $N$-acetyl- $\alpha$-D-galactosamine residues (29).

The four glycoproteins proved to be potent inhibitors of cholesterol crystal growth in model bile (Fig. 5), actually the most potent inhibitors isolated from human bile so far. They reduced the kinetics of crystallization (growth rate) and the final crystal concentration with the $28-\mathrm{kD}$ protein showing the strongest inhibiting effect. Even our protein with the lowest inhibiting potency performed better than the recently reported $58 / 63-\mathrm{kD}$ heterodimer (6). Promoter proteins, although known to be present in the lectin-bound protein fractions (5), were not found among the crystal-binding proteins.

Crystal morphology was significantly changed in the presence of lectin-bound proteins favoring growth of euhedral triclinic crystals with smooth surfaces which tended to form regular aggregates or compact microliths. We found similar forms of crystals as those described by Toor et al. (30), who reported an increase in incidence of irregular polycyclic crystals with multiple spiral, edge, and stepwise dislocations when cholesterol supersaturation of model bile was raised. Using a supersaturated model bile with a cholesterol saturation index of 1.3, we found that these types of crystal structures predominated in the control experiment but were significantly less frequent in the presence of effector proteins. The crystal morphology we describe is also in agreement with other scanning electron microscopy studies of native and model human biles $(31,32)$.

The four proteins form a new subgroup of inhibitors among the lectin-bound protein fractions of human gallbladder bile. Since only isoforms with no or weak charges at the $\mathrm{pH}$ of model bile are found on the crystals, we concluded that the binding of proteins to cholesterol crystals is controlled by hydrophobic interactions. Proteins might attach to the most rapidly growing sites of the crystals, like spiral and step dislocations (30) of the thermodynamically stable monohydrate plates. However, they might also interfere with other rapidly growing sites of structures found in early cholesterol crystallization (17). This mechanism would require only small amounts of inhibitors. Also the final crystal concentration would be decreased, since a higher activity of free cholesterol in bile would be required for further apposition of cholesterol molecules to the crystal $(33,34)$. This interpretation is supported by the changes of both crystal growth curve parameters, and, recalling the data on cholesterol crystal structure and growth thermodynamics $(35,36)$, could explain the observed preference for compact euhedral crystals.

Other evidence has been reported which indicates the special property of glycoproteins to inhibit crystal growth in biological systems. In sera of polar fish, "antifreeze proteins" prevent the formation of ice $(37,38)$. They presumably adsorb to ice crys- tals, thus inhibiting the normal propagation of ice-growth steps or layers across the surface (39). A similar mechanism may also apply to freeze tolerance in insects (40). Glycoproteins regulate the precipitation of calcium salts in bone and dentin formation (41). Regarding stone formation in humans, three different inhibitor proteins of calcium carbonate or oxalate precipitation have been isolated: a $14-\mathrm{kD}$ glycoprotein inhibitor prevents formation of calcium oxalate nephrolithiasis in healthy subjects $(42,43)$, a small acidic glycoprotein from human pancreatic calculi inhibits calcium carbonate precipitation $(44,45)$, and, finally, a small $(<10-\mathrm{kD})$ glycoprotein isolated from cholesterol gallstones tightly binds bile pigment and strongly inhibits precipitation of calcium carbonate in vitro (46).

Preliminary data from our laboratory indicate that the cholesterol crystal-binding proteins are subunits of polymeric human $\operatorname{IgA}(47,48)$. A full characterization of these proteins is currently prepared for publication.

The observations reported in this paper may contribute to the understanding of cholesterol gallstone pathogenesis. The irregular aggregates and the clusters of crystals that predominated in the populations grown without inhibitor proteins may form a nidus for deposition of biliary mucus, pigment, and precipitates of calcium and its sensitive anions, bilirubinate and carbonate. All these compounds, which are major constituents of biliary sludge (49), are almost always found in the centers of cholesterol gallstones (50). We found inhibitor proteins increasing the frequency of compact crystals and regular aggregates even in those samples that contained potent antagonistic promoting factors (5). Compact crystals may be considered as the most effective deposit for cholesterol in bile and are normally removed by gallbladder contraction. In human gallstone disease, highly correlated with gallbladder motor dysfunction (51), these crystals may accumulate in bile and provide the substrate for gallstone formation. The observed crystal morphologies correlate to scanning electron microscopy studies of human gallstones (52), showing a well-ordered arrangement of compact crystals in slowly growing solitary cholesterol gallstones. In contrast, in fast-growing multiple cholesterol stones, unsettled crystals forming random aggregates were found being radially arranged in a perpendicular position to the center of the hemisphere.

We conclude that depending on the balance of promoters and inhibitors in bile inhibiting activity either impedes cholesterol crystallization or retards subsequent mechanisms of gallstone formation thus favoring well-ordered arrangements of stone-forming crystals.

\section{Acknowledgments}

We thank H. G. Hollweg for assistance in electron microscopy, I. Franz for skillful technical assistance, and $\mathrm{K}$. Willmes for assistance in statistical analysis.

This work was supported by the Deutsche Forschungsgemeinschaft (Bu 822).

\section{References}

1. Holzbach, R. T., A. Kibe, E. Thiel, J. H. Howell, M. Marsh, and R. E. Hermann. 1984. Biliary proteins. Unique inhibitors of cholesterol crystal nucleation in human gallbladder bile. J. Clin. Invest. 73:35-45.

2. Kibe, A., R. T. Holzbach, N. F. LaRusso, and S. J. T. Mao. 1984. Inhibition of cholesterol crystal formation by apolipoproteins in supersaturated model bile. Science (Wash. DC). 225:514-516. 
3. Gallinger, S., P. R. C. Harvey, C. N. Petrunka, R. G. Ilson, and S. M. Strasberg. 1987. Biliary proteins and the nucleation defect in cholesterol cholelithiasis. Gastroenterology. 92:867-875.

4. Busch, N., H. Tokumo, and R. T. Holzbach. 1990. A sensitive method for determination of cholesterol crystal growth using model solutions of supersaturated bile. J. Lipid Res. 31:1903-1909.

5. Busch, N. N. Matiuck, S. Sahlin, S. P. Pillay, and R. T. Holzbach. 1991. Inhibition and promotion of cholesterol crystallization by protein fractions from normal human gallbladder bile. J. Lipid Res. 32:695-702.

6. Ohya, T., J. Schwarzendrube, N. Busch, S. Gresky, K. Chandler, A. Takabayashi, H. Igimi, K. Egami, and R. T. Holzbach. 1993. Isolation of a human biliary glycoprotein inhibitor of cholesterol crystallization. Gastroenterology. 104:527-538.

7. Turley, S. D., and J. M. Dietschy. 1978. Re-evaluation of the $3 \alpha$-hydroxysteroid dehydrogenase assay for total bile acids in bile. J. Lipid Res. 19:924-928.

8. Takayama, M., S. Itoh, T. Nagasaki, and I. Tanimizu. 1977. A new enzymatic method for determination of serum choline-containing phospholipids. Clin. Chim. Acta. 79:93-98.

9. Allain, C. C., L. S. Poon, C. S. Chan, W. Richmond, and P. C. Fu. 1974 Enzymatic determination of total serum cholesterol. Clin. Chem. 20:470-475.

10. Bradford, M. M. 1976. A rapid and sensitive method for the quantitation of microgram quantities of protein utilizing the principle of protein-dye binding. Anal. Biochem. 72:248-254.

11. Smith, P. K., R. I. Krohn, G. T. Hermanson, A. K. Mallia, F. H. Gartner, M. D. Provenzano, E. K. Fujimoto, N. M. Goeke, B. J. Olson, and D. C. Klenk. 1985. Measurement of protein using bicinchoninic acid. Anal. Biochem. 150:7685 .

12. Laemmli, U. K. 1970. Cleavage of structural proteins during the assembly of the head of bacteriophage T4. Nature (Lond.). 227:680-685.

13. Heukeshoven, J., and R. Dernick. 1985. Simplified method for silver staining of proteins in polyacrylamide gels and the mechanism of silver staining. Electrophoresis. 6:103-112.

14. Bjellqvist, B., K. Ek, P. G. Righetti, G. Gianazza, A. Goerg, R. Westermeier, and W. Postel. 1982. Isoelectric focusing in immobilized $\mathrm{pH}$ gradients: principle, methodology and some applications. J. Biochem. Biophys. Methods. 6:317-339.

15. Carey, M. C. 1978. Critical tables for calculating the cholesterol saturation of native bile. J. Lipid Res. 19:945-955.

16. Woolson, R. F. 1987. Statistical Methods for the Analysis of Biomedical Data. John Wiley and Sons Inc., New York. 1-513.

17. Konikoff, F. M., D. S. Chung, J. M. Donovan, D. M. Small, and M. C. Carey. 1992. Filamentous, helical, and tubular microstructures during cholesterol crystallization from bile. Evidence that cholesterol does not nucleate classic monohydrate plates. J. Clin. Invest. 90:1155-1160.

18. Carey, M. C., and D. M. Small. 1978. The physical chemistry of cholesterol solubility in bile: relationship to gallstone formation and dissolution in man. $J$. Clin. Invest. 61:998-1026.

19. Holzbach, R. T., and N. Busch. 1991. Nucleation and growth of cholesterol crystals. Kinetic determinants in supersaturated native bile. Gastroenterol. Clin. North Am. 20:67-84.

20. Womack, N. A. 1971. The development of gallstones. Surg. Gynecol. \& Obstet. 133:937-945.

21. Carey, M. C. 1993. Pathogenesis of gallstones. Am. J. Surg. 165:410419.

22. Groen, A. K., J. P. J. Stout, J. A. G. Drapers, F. J. Hoek, R. Grijm, and G. N. J. Tytgat. 1988. Cholesterol nucleation-influencing activity in T-tube bile Hepatology. 8:347-352.

23. Groen, A. K., C. Noordam, J. A. G. Drapers, P. Egbers, P. L. M. Jansen, and G. N. J. Tytgat. 1990. Isolation of a potent cholesterol nucleation-promoting activity from human gallbladder bile: role in the pathogenesis of gallstone disease. Hepatology. 11:525-533.

24. Offner, G. D., D. Goug, and N. H. Afdhal. 1994. Identification of a 130 kilodalton biliary concanavalin A binding protein as aminopeptidase N. Gastroenterology. 106:755-762.

25. Harvey, P. R. C., G. A. Upadhya, and S. M. Strasberg. 1991. Immunoglobulins as nucleating proteins in the gallbladder bile of patients with cholestero gallstones. J. Biol. Chem. 266:13996-14003.

26. Abei, M., P. Kawczak, H. Nuutinen, A. Langnas, J. Svanvik, and R. T. Holzbach. 1993. Isolation and characterization of a cholesterol crystallization promoter from human bile. Gastroenterology. 104:539-548.

27. Pattinson, N. R., and K. E. Willis. 1991. Effect of phospholipase $C$ on cholesterol solubilization in model bile. A concanavalin A-binding nucleation- promoting factor from human gallbladder bile. Gastroenterology. 101:13391344.

28. Chijiiwa, K., A. Koga, T. Yamasaki, K. Shimada, H. Noshiro, and F. Nakayama. 1991. Fibronectin: a possible factor promoting cholesterol monohydrate crystallization in bile. Biochim. Biophys. Acta. 1086:44-48.

29. Goldstein, I. J., and R. D. Poretz. 1986. Isolation, physiological characterization, and carbohydrate-binding specifity of lectins. In The Lectins: Properties, Functions, and Applications in Biology and Medicine. I. E. Liener, N. Sharon, and I. J. Goldstein, editors. Academic Press, Inc. Orlando, FL. 33-247.

30. Toor, E. W., D. F. Evans, and E. L. Cussler. 1978. Cholesterol monohydrate growth in model bile solutions. Proc. Natl. Acad. Sci. USA. 75:6230-6234.

31. Osuga, T., O. W. Portman, K. Mitamura, and M. Alexander. 1974. A morphologic study of gallstone development in the squirrel monkey. Lab. Invest. 30:486-493.

32. Osuga, T., K. Mitamura, S. Miyagawa, N. Sato, S. Kintaka, and O. W. Portman. 1975. A scanning electron microscopic study of gallstone developmen in man. Lab. Invest. 31:696-704.

33. Higuchi, W. I., C. L. Liu, Y. Adachi, N. A. Mazer, and P. H. Lee. 1990. Equilibrium dialysis studies on aqueous taurocholate-lecithin solutions: further validation of the method. Hepatology. 12:45s $-49 \mathrm{~s}$.

34. Busch, N., and S. Matern. 1991. Current concepts in cholesterol gallstone pathogenesis. Eur. J. Clin. Invest. 21:453-460.

35. Craven, B. 1976. Crystal structure of cholesterol monohydrate. Nature (Lond.). 260:727-729.

36. Shipley, G. G. 1990. Structural studies of the lipid components of bile. Hepatology. 12:33s-37s.

37. DeVries, A. L. 1986. Antifreeze glycopeptides and peptides: interactions with ice and water. Methods Enzymol. 127:293-303.

38. Feeney, R. E., and T. S. Burcham. 1986. Antifreeze glycoproteins from polar fish blood. Annu. Rev. Biophys. Biophys. Chem. 15:59-78.

39. Eastman, J. T., and A. L. DeVries. 1986. Antarctic fishes. Sci. Am. 1986:96-103.

40. Storey, K. B., and J. M. Storey. 1988. Freeze tolerance in animals. Physiol. Rev. 68:27-84.

41. Veis, A. 1984. Bones and teeth. In Extracellular Matrix Biochemistry. K. A. Piez and A. H. Reddi, editors. Elsevier-North Holland, New York. 329374.

42. Nakagawa, Y, V. Abram, F. J. Kezdy, E. T., Kaiser, and F. L. Coe. 1983. Purification and characterization of the principal inhibitor of calcium oxalate monohydrate crystal growth in human urine. J. Biol. Chem. 258:12594-12600.

43. Nakagawa, Y., M. Ahmed, S. L. Hall, S. Deganello, and F. L. Coe. 1987 Isolation from human calcium oxalate renal stones of nephrocalcin, a glycoprotein inhibitor of calcium oxalate crystal growth: evidence that nephrocalcin from patients with calcium oxalate nephrolithiasis is deficient in $\gamma$-carboxyglutamic acid. J. Clin. Invest. 79:1782-1787.

44. De Caro, A., L. Multigner, H. Lafont, D. Lombardo, and H. Sarles. 1984. The molecular characteristics of human pancreatic acidic phosphoprotein that inhibits calcium carbonate crystal growth. Biochem. J. 222:669-677.

45. Montalto, G., J. Bonicel, L. Multigner, M. Rovery, H. Sarles, and A. De Caro. 1986. Partial amino acid sequence of human pancreatic stone protein, a novel pancreatic secretory protein. Biochem. J. 238:227-232.

46. Shimizu, S., B. Sabsay, A. Veis, J. D. Ostrow, R. V. Rege, and L. G. Dawes 1989. Isolation of an acidic protein from cholesterol gallstones, which inhibits precipitation of calcium carbonate in vitro. J. Clin. Invest. 84:1990-1996.

47. Busch, N., F. Lammert, J. Schwarzendrube, H. U. Marschall and S. Matern. 1994. Evidence for the $74 \mathrm{kD}$ inhibitor protein of cholesterol crystallization to be the secretory component of human biliary immunoglobulin A. Hepatology. 20:116a. (Abstr.)

48. Busch, N., F. Lammert, I. Franz, J. Schwarzendrube, H. U. Marschall, and S. Matern. 1995. The $63 \mathrm{kD}$ and $28 \mathrm{kD}$ crystal binding protein fractions represent the heavy and light chains of human biliary immunoglobulin A. Gastroenterology. 108:407a. (Abstr.)

49. Lee, S. P., K. Maher, and J. F. Nicholls. 1988. Origin and fate of biliary sludge. Gastroenterology. 94:170-176.

50. Been, J. M., P. M. Bills, and D. Lewis. 1979. Microstructure of gallstones. Gastroenterology. 76:548-555.

51. Van der Werf, S. D. J., G. P. van Berge Henegouwen, D. M. H. Palsma and A. T. Ruben. 1987. Motor function of the gallbladder and saturation of duodenal bile. Neth. J. Med. 30:160-171.

52. Wolpers, C., and A. F. Hofmann. 1993. Solitary versus multiple cholesterol gallbladder stones. Mechanisms of formation and growth. Clin. Investig. 71:423434 